\title{
Leaving Vipassana Meditation
}

\author{
Masoumeh Rahmani
}

\section{Introduction}

This chapter explores the disaffiliation narratives of former members of one of the most successful international Buddhist organisations - S.N. Goenka's (1924-2013) Vipassana meditation movement. To date, Goenka's network is the largest donor-funded Vipassana organisation with over 170 official, and over 130 non-official centers worldwide. These centers offer courses of varying durations (3-6o day), thought the standard ten-day retreats mark one's entry into this organisation, and hence they are the most frequently held and best attended (Dhamma 2017). Around the globe, Goenka's courses are conducted more or less identically; they all follow the same guidelines and are taught via pre-recorded audio and video footage of Goenka.

Goenka's teachings are theoretically underpinned by the basic Buddhist doctrines of the Four Noble Truths and his selective interpretation of the Buddhist text, Satipatthana Sutta in light of the Theravada text, Abhidhamma and "the Path of purification" (Rahmani and Pagis 2015). According to Goenka, human existence is characterised by suffering, resulting from attachment and aversion to things that are impermanent. He therefore follows the Buddhist premise that all phenomena are marked by suffering (dukkha), impermanence (anicca), and not-self (anatta). Goenka asserts that insight into the true nature of reality, can be gained through the observance of Buddha's Noble Eightfold Path, which is divided into three sections: morality (sila), concentration (samadhi), and wisdom (panna). Astandard ten-day course is structured meticulously in order to practice these three stages and to develop insight into the true nature of reality, as it is understood within the Theravada tradition (Pagis, 2010).

However, Goenka (1997:12) argues that a mere intellectual understanding of these concepts and processes does not produce "real wisdom," and therefore cannot liberate one from suffering; rather one must understand the true at an experiential and embodied level. Hence, students are advised to invest more time in meditation than reading or engaging in "useless intellectual games." This epistemic strategy undergirds much of Goenka's enterprise including his continuous effort to abstract his movement and its teachings from the category 
of religion so as to promote the practice as a "rational," "non-sectarian," selfdevelopment "tool," which is "universal" and "does not involve religious conversion."

Finally, even though Goenka adopts a world-affirming and scientific language to transmit the "teachings of the Buddha" to his non-Buddhist audience, the ultimate goal of nibbana is never left behind in his discourses. In fact, Goenka (1997: 1) constantly vacillates between emphasising the practical benefits of Vipassana meditation (for example, clarity of mind) and promoting this practice as a transformative tool for achieving enlightenment. While this vacillation often led new students to question the purpose of the technique, there was no such ambivalence in the mind of committed meditators who undeniably pursued enlightenment. This chapter is primarily concerned with reporting the narratives of the latter group; those who constructed a life around this practice, indicated high levels of commitment during their involvement, and had the experience of attending a minimum of three ten-day courses and a maximum of twenty, ten-day courses.

\section{Previous Research and Empirical Material}

In comparison to the proliferation of books and doctoral dissertations theorising the transformative efficacy of meditation and the process of conversion to Buddhism, the process of exit from the Buddhist world-view is extremely underdeveloped and in dire of scholarly attention. Perhaps Tim Mapel's (2007) study, "The Adjustment of Ex-Buddhist Monks to Life after Monastery" is the closest approximation to this topic. However, as the title suggest, Mapel's work is primarily focused on the process of adjustment post exit (such as employment, building new relationships, developing intimacy, etc.) and does not explore disaffiliation in itself. ${ }^{1}$ This gap in the literature is, in part, due to the temporal "newness" of Buddhism/Buddhist meditation in western context; it is also contingent to the positive sociopolitical discourse surrounding meditation, which, in comparison to the "cult controversies" of the 1960s-1970s, has not provoked a sense of (public) immediacy for this phenomenon to be investigated. Considering the diversity of Buddhist traditions/groups active in contemporary western societies and the rate at which disengagement occurs from these groups (particularly short-lived engagements), a wealth of unknown is

1 As an ex-monk himself, Mapel does not make any reference as to whether he or any of the five western ex-monks in his study had deconverted. 
yet to be excavated and explored through interdisciplinary approaches (anthropology, gender studies, sociology, and psychology).

Following Wright and Ebaugh (1993: 120) I use the terms affiliation and disaffiliation to refer to the formal processes of joining and leaving an organisation; both terms are neutral to the processes of personal transformations prompted by one's the acceptance or rejection of a system of meaning. Conversely, the terms conversion and deconversion are used to delineate the gradual process of migration to a new universe of discourse (Snow and Machalek, 1983) and the creation of a new self-concept. ${ }^{2}$ As "a system of common or social meanings" the universe of discourse provides the individual with necessary recourse for self-construction, reorientation towards world, and the interpretation of experiences, events, and the action of self and others.

This chapter prioritised a narrative analysis approach, and presents the findings in light of the linguistic and institutional features of the movement. The chapter is not concerned with speculating the cause of disengagement or with the role of factors (social, gender, etc.) in the disengagement process.

The findings presented here are based on my ethnographic fieldwork and indepth interviews with twenty-six current and former Vipassana meditators in New Zealand (Rahmani 2017). Participant recruitment took place over a period of two-years and involved theoretical and snowball sampling method. In what follows, I depict the contours of Vipassana disaffiliation narratives, and, based on the existing material, I suggest that deconversion is (relatively) a rare exit pattern from this movement.

Many facets of Vipassana disaffiliation narratives correspond with previous religious disengagement literature (Barbour 1994; Bromley 1998; Streib et al. 2011). Former Vipassana meditators commonly described the process of disaffiliation as a gradual, lengthy, and emotionally consuming. Their narrative plots contained description of major (or series of minor) events that eventually disturbed the practitioners' taken-for-granted assumptions, predominantly about the institutional aspects of the movement and/or the movement's leadership and other authoritative figures (Wright 2007). As a result, disaffiliates

2 By using the term self and self-concept, I follow the largely unchanged footprints of Mead (1934 cited in Gecas 1982: 3) who sees the former not as an organism, but as a "reflexive phenomenon that develops in social interaction and is based on the social character of human language," and the latter as the "product" of this reflexive activity. 
heavily relied on "moral criticism" (Barbour 1994: 51) as a rhetorical strategy to vindicate their decision to depart. For instance, one participant anchored his disaffiliation on the premise of feeling "deceived" into believing that the movement offered an "open teaching" yet gradually discovered the "hidden structures" within it, such as the demand of complete observance of sila including celibacy.

However, while "intellectual doubt" is often considered as one of the main ingredients in the disengagement process and its narrative ${ }^{3}$ (Barbour 1994; Fazzino 2014; Streib et al. 2011), former Vipassana meditators rarely harbored doubts about the movement's ideologies, or used intellectual doubt as a rhetoric to plot their narratives. In fact, while some rendered the "discursive" components of the teachings problematic, almost all (except one: Luke) participants praised the "essence of the technique" as a "universal," "indisputable," "and "incredibly on the ball" for "understanding reality." Instead, Vipassana disaffiliation narratives were marked by a sense of ambivalence indicating the ex-members' (often ongoing) unequivocal trust in the transformative efficacy of the technique, and a certain doubt about their own abilities to achieve the desired/propagated goals.

The theme of "self-doubt" was therefore ubiquitous across the narratives of all those consulted for this research. In most instances, self-doubt seemed to be prompted by, and interlaced with, the movement's ambiguous discourse surrounding progress. On a Vipassana course, students are constantly discouraged from developing expectations, yet are repeatedly reassured that "results are bound to come" and they will experience some sort of change if they practice the technique "properly" (Goenka 1997: 33). Students are told that progress cannot be measured by the types of sensations one experiences (subtle or gross); rather by the sense of "equanimity" they develop in response to their sensations (that is, how they handle their cravings and aversions) - which is itself difficult to measure (Pagis 2008: 174). Despite these assertions, there are various descriptions in Goenka's instructions that are taken by practitioners as yardsticks such as descriptions of bhanga, which is the experience of total dissolution of the apparent solidity of the body into waves of pleasant sensations:

Kevin: ${ }^{4}$ I spent a lot of time doubting whether I'd ever be able to um correctly perform the technique (...) you know, you're bound to be seeing

3 This may be related partially to the theological features of the traditions in which these studies were commonly grounded.

4 Pseudonyms are used to ensure the anonymity of those who requested it. I have also respected the decision of other participants who desired to be named. 
some results, and really it's quite, quite subtle (...) I've heard people talking about it you know, "oh I've experience the bhanga or dissolution." Not me! [hah] Plus, you know, I was never really going for that, I knew I was a plonker (...) I kind of accepted it.

More profoundly, however, self-doubt reflected the ex-member's ambivalence about their progress towards enlightenment:

Damian: I had doubts about the teachings, not that it didn't work, but that there was a propaganda element within the teaching of retreats that made you believe you were near to a break through (...) and you thought (...) "I'm gonna get there, I'm gonna like um get enlightened" (...) and then on the last day he [Goenka] says "well it is a long path (...) maybe a lifetime path" (...) So I had doubt about my progress (...) I felt that in fact I was going backwards.

A thematic exploration of these case studies highlights two common disaffiliation trajectories, indicating two distinct ways in which former members resolved their doubts, plotted their disaffiliation narratives, and articulated their current self-concepts. These include (1) "drifters in samsara," and (2) "pursuers of the gateless gate." While these two trajectories are presented in juxtaposition to one another, they should not be construed as watertight categories; rather as a black and white reflection of the ex-members' (re)orientations towards enlightenment and the various positions they occupied along the traditional-modernist spectrum after exit. Note, however, that in addition to the enduring trace of the Buddhist language, all narratives shared one underlying similarity, which involved the giving up and letting go of an obsession with enlightenment.

The narratives of "drifters in samsara" indicated a movement towards a more traditional Theravada discourse with a conception of enlightenment as a transcendental reality and an impossibly distant ideal. They metaphorically perceived Vipassana meditation as a raft carrying them across the ocean of samsara towards the distant shore of nibbana. For many of them, the path to enlightenment was tied to the mastery of emotions and cravings (for example, sexual passion). As such, their self-doubt seemed entangled with a perceived inability to eliminate patterns of craving (eradicate sankharas). Take for instance, the following passage:

Damian: In my current life, there's an element of resignation... feeling that not much can change for me in the rest of my life... what Vipassana 
showed me was that the process of transformation is very, very slow... and the karmic history of each consciousness in general is quite vast... so I feel a bit resigned to the shit parts of me (...) which in a funny way was a logical outcome of Vipassana, because it's all about acceptance (...) have you heard of Ram Dass? (...) he'd been in India, where he went extensively and he'd come back and he was on a bus and he saw some woman and he though "hmm, she's pretty attractive" and then he had this self-reflection and he, he felt like "after all of this how come I haven't managed to, why haven't I been able to get past this? I still got this sort of sexual interest" (...) and it kind of echoes what I'm trying to say is that, you know you can do realms and realms of spiritual practice but (...) wind up struggling with the same old junk that you were struggling with when you were a teenager.

As this passage demonstrates, the narratives of the drifters in samsara indicated the participants' commitment to certain theological concepts (for example, reincarnation, karma, sankhara), which they directly used to rationalise abandoning the much-desired goal of enlightenment in the present life. Yet, while self-doubt or a perceived lack of self-mastery had evidently exhausted these individuals' enthusiasm, they nevertheless continued idealising enlightenment as a transcendental reality - it is just that the goal was postponed to another life.

An outstanding component of these narratives was enigmatic reports and side stories of "ghost visitations," and/or "past-life experiences," which the drifters in samsara often voluntarily launched into. A linguistics and thematic exploration of these narratives highlights the participants' need for a new conceptual framework to understand the self, and hence achieve a sense of selfacceptance. For instance, Damian (40s, former member) noted, "often when I felt negative, I realised that (...) some of my feelings are colored by visitations by ghosts and other psychic entities." These experiences led him to question the idea that "everything you feel is absolutely your responsibility." Yet, even though these individuals engaged in practices that may be considered unorthodox from Goenka's viewpoint (for example, looking for causal explanations, or rejecting individual responsibility), in most instances, participants' search for alternative frameworks did not land them outside the Buddhist tradition. In fact, participants who shared these narratives tended to draw from the Jatakas and argued that such perspectives are in perfect harmony with traditional Theravada conventions.

Conversely, the narratives of the "pursuers of the gateless gate" indicated a reorientation towards an understanding of enlightenment that affirmed the 
ordinary life as a site for awakening. For these former Vipassana meditators, enlightenment did no longer represent an unattainable transcendental reality; rather something intrinsic and already existing. This point represented the pinnacle of their stories, and was regarded as a "highly liberating" realisation. In simple terms, these individuals resolved their uncertainties by replanting enlightenment within an immanent framework and effectively bringing this goal within reach. Such understandings correspond with modernist Zen interpretations of D.T. Suzuki's (1870-1966) legacy - and West Coast American interpretations of Vipassana pioneered by Jack Kornfield (1945-).

The pursuers of the gateless gate also stressed a new approach to meditation. They rendered the act (sitting) meditation "counterproductive" and a barrier to living life and having a "pulsate experience" of it. Instead, they took the meditation "off the cushion," and aimed for implementing the insights gained from the practice into every aspect of the ordinary life. An outstanding linguistic feature of these narratives was the positive context in which "life" was spoken of. This characteristic should be interpreted in light of their biographical stories, which magnified an intense devotion to the practice (during involvement), due to which most developed resentment towards mundane aspects of life such as earning a living. In the most extreme scenario, after leaving Goenka's movement, one participant (Kovido, 6os) ordained in the Thai Forest tradition of Ajahn Chah in order to make the pursue of enlightenment his fulltime career:

Kovido: I spent years trying to get enlightened. You know and went through various teachers (...) and then kind of actually then coming back to this, the teaching of that, actually we're ok as we are. You know. That actually, what the Buddha realised was that it's something that is already here, it's already existing (...) something to do with living fully you know, I'm a human being (...) this incarnation or other incarnations, it kind of makes sense (...) But it's about living fully really and not suffer.

Contrary to the nuances of self-acceptance encountered in Damian's narrative, which was predicated under the hegemony of Theravada Buddhism, the pursuers of the gateless gate rehearsed narratives reconstructed within what Gleig (2010) refers to as a "feminine" approach to Buddhism. Such an approach, according to Gleig (2010:120), promotes a "feminine-associated appreciation of self-acceptance, interdependence and healing." These shifts are most notably evident in Jack Kornfield's (200o) innovations and reinterpretations of Vipassana, which explicitly condemns western practitioners' tendencies to misuse Buddhist ideals to feed their harsh and unhealthy "inner-critic" (Kornfield 
2000 cited in Gleig 2010: 119-121). Instead, Kornfield calls for a metaphorical reading of Buddhist enlightenment which he frames as "mature spirituality" or "embodied enlightenment," which aims not to transcend the "pain of human life," but to acknowledge and develop awareness, and to embody human wholeness in everyday life (cited in Gleig 2010: 121). The following passage from Karen's (30s, former member) narrative encapsulates these points:

Karen: At that time of meditating four or five hours a day, I was thinking, that's what gets you to nirvana (...) you sit on your bum until I don't know what happens I don't know, someone pops a party cracker, it's done (...) from my experiences it's [enlightenment] a total pile of bullshit sales pitch that is (...) enticing people to sit their asses on the cushion and donate their money to different corporations (...) once we step out of the way and actually allow ourselves to let go of the things we hold dear (...) once that's gone, there only is, there's only nirvana. Even the not seeing nirvana is nirvana (...) it's so sad because it makes people think "I'm not good enough," "I'm not there yet."

The final prevalent characteristic of the narratives in this group is the theme of Perennialism - the idea that there is a shared essence, a mystical core or an ultimate reality behind the plurality of religious and philosophical traditions, which is often conceived as a non-dual absolute consciousness (Sharf, 2015: 477). Pursuers of the gateless gate insisted on presenting selves that are open and appreciative of religious diversity, knowing that they all teach and preach of the same underlying "essence." This feature stood in sharp contrast to the language of the drifters in samsara who explicitly and implicitly demonstrated their commitment to the Theravada Buddhist perspective (for example, some expressed prejudice towards the Tibetan Mahayana traditions for its "circuslike" rituals, or rendered meditational methods "wishy-washy").

In sharp juxtaposition to the two categories described above, the language of only one participant (Luke, 4os, former member) leaped outside of the movement's (and the Buddhist) universe of discourse, and landed within a more secular, humanistic one. While a thorough exploration of this story merits its own chapter, it is important to demonstrate why this narrative warrants the "deconversion" label. As hinted above, even though some disaffiliates reconfigured the concept of enlightenment, they did not completely reject the doctrine, or any other Buddhist concept of that matter. Against this backdrop, Luke confidently repudiated the technique on grounds of theory and practice using striking narrative asides such as stories about a fellow student who committed suicide, in parallel to his own experience and suffering: "I just became 
suicidal within the first year of practice (...) and bizarrely I thought that going deeper into the practice was my solution to the problem." In essence, Luke constructed a narrative that centralised on crisis and trauma, which he perceived to be the resultant of the meditational practice:

Luke: The goal [of the practice] is to fracture the psyche in some particular way and um uproot it. But there's no particular place to put it (...) Where am I in all this? (...) the notions of "you don't exist," "oh there's no I." Well, practically speaking there is an "I" (...) practically speaking I do exist, and um, really as well (...) So I won't go along with this notion of, "oh there's no I." Because, who's suggesting there's no I? It's either Goenka or me suggesting that there's no I.

Luke's narrative, as a whole, emphasised the trauma caused by the displacement of self (self is detached from an embodied experience of the body), leading to alienation or a point where one does no longer identify with the body, emotions, sensations, and the mind. While this detached perspective is essential for understanding the true nature of the self (not-self), Luke used it as an anchoring point to position himself against the movement, legitimise his exit, and construct/represent a "rational" sense of self. On a linguistic level, Luke rejected the concept of not-self by posing an epistemological question - "who's suggesting there is no I." Luke sought to dismiss the concept of not-self - and by extension, Goenka - by proving the ontological existence of the self. To achieve this, Luke objectified the "self" (for example, "psyche"), subjected it to rational inquiry (elsewhere he added, "there is an I, and what does it do?"), and even sought to metaphorically ascribe locality to it ("no particular place to put it"). On a more implicit level, Luke rejected not-self, and reinforced the reality of self by performing the role of the Cartesian cogito.

This articulation is born out of two decades of retrospective meaning making and in-depth critical engagement with both insider and outsider literature - a typical phase of disengagement process that has been previously described as "paradigmatic work" (Fazzino 2014: 258). However, in this feature, Luke was not alone. Other disaffiliates in this research indicated a sudden appetite for intellectual knowledge, which commonly reflected their need for an alternative resource to construct selves post exit, and/or a mere desire to assess the movement's claims and to locate it within the historical Buddhist context.

The abovementioned trends in Vipassana disaffiliation narratives (theme of self-doubt, the absence of serious intellectual disputes of the movement's 
beliefs and doctrine, and the infrequency of deconversion), support Bromley's (1998) tripartite model which links exit role types (I defectors, II whistle-blowers, and III apostates) and organisational structures (I allegiant, II contestant, and III subversive). In short, Bromley (1998) argues that the manner in which an individual leaves a NRM is largely determined by the level of tension between the organisation and the context of its host society.

Seen through the prism of Bromley's typology, the typical exit pattern from Goenka's Vipassana organisation could be considered as defectors, who leave allegiant organisations. According to Bromley (1998: 148), "The high level of legitimacy and moral rectitude attributed to allegiant organisations allows them to translate problems into organisational terms and categories that place primary responsibility for failure on the member." As a result, the defector may be left incapable of articulating grievances or validating claims without meaningful alternative resources (Bromley 1998: 147) and they do not pose a major threat to their former group; instead, they continue to respect, and reaffirm the organisations values and goals after exit - as it has been the case of most disaffiliates.

Regardless of the movement's fast-and-loose associations with Buddhism, which essentially allows it to relish the positive image of the tradition (peacefulness, direct link to the Buddha) and discard its other connotations, Vipassana in New Zealand had arguably enjoyed a certain degree of legitimacy from its early years of establishment (having been officially registered as an "educational institute" at the local council). More importantly, unlike other religious organisations (such as the Mormon church and The Family), Goenka's organisation has not been the target of any noteworthy scandals or lawsuits, which helps to preserve their respectable image globally. Furthermore, the movement arguably benefits from a low-tension relation with other religious organisations by the virtue of its proselytisation tactics (word of mouth), which makes the center accessible to specific demographics/subcultures, and covert to the more culturally/religiously conservative sectors of the population.

Not surprisingly, Goenka's organisation exerts control over disputes and has various interpersonal guidelines and strategies to prevent the spread of controversial ideas among members. According to a number of participants, potential "claimmakers" are placed on deferral lists and any behavior that may lead to the spread of disputes are said to cause "bad karma." Moreover, the centre in New Zealand is said to have supplemented a position of a social worker (presumably psychiatrist/psychologist) in order to control post-participation psychosomatic episodes. As shown, the organisation administrates the exit narrative, and enforces its emic categories that effectively places the failure on 
the member - hence the significance of self-doubt. According to the Vipassana Teacher I interviewed, "If they stop, it's not the technique that's the problem, it's the person." Together, these structural features (linguistic and organisational) could be said to constrain the process of exit and its interpretive narrative in intricate ways.

Finally, while Bromley's typology corresponds with the linguistic and institutional features of the movement, there does remain a point of departure. In reference to the defector role, Bromley (1998:148) posits, "The absence of preexisting oppositional groups significantly restricts the political and economical opportunity for a former member career." I would argue that in the case of international Buddhist organisations (and possibly Buddhism in general), we are witnessing a diverging trend. That is, the positive discourse surrounding meditation - promoted by psychologists and channeled through various outlets - has created a fertile field for former Buddhists to venture in, and benefit from their ex-member identities. In addition to ex-monks' apparent career choice in various subfields of psychology, the development of meditation apps and "Dhamma counseling" via Skype (for $\$ 150$ US per 50 minute) by ex-Buddhist monks are a case in point.

\section{4}

\section{Conclusion}

This chapter explored the narratives of individuals who departed from Goenka's movement after years of intensive commitment. My analysis showed that in the vast majority of instances, disaffiliation did not result in total rejection of the movement's doctrines; nor did it result in complete migration outside of its universe of discourse. I posit that consequential to Vipassana's ideologies and linguistic strategies (including its epistemic ideology, claims of rationality, universality, and instrumentality, rejection of religious labels and categories, emphasise on self-development and individual autonomy, and more importantly, its propagation of meditation as a mean to end human suffering) Goenka's movement occupies a low-tension niche within the cultural context of New Zealand, which itself supports these dispositions. As a result of this harmony, not only does the movement enforce its emic categories on exit narratives, but it also continues to influence the world of many of its former members. However, this chapter has primarily gazed at religious disengagement through the keyhole of language and was insensitive to other factors influencing this process. Future studies should cast a wider net in order to gain a more holistic understanding of exit from this tradition. 


\section{References}

Barbour, J.D. 1994. Versions of Deconversion: Autobiography and the Loss of Faith. Charlottesville: University of Virginia Press.

Bromley, D.G. 1998. Linking Social Structure and the Exit Process in Religious Organizations: Defectors, Whistle-Blowers, and Apostates. Journal for the Scientific Study of Religion. 37:1, 145-160.

Dhamma. "Course schedule." Vipassana Meditation Germany. At https://www.dham ma.org/en/schedules/schdvara. Accessed 1/10/2017.

Gecas, V. 1982. The Self-Concept. Annual Review of Sociology. 8:1, 1-33.

Gleig, A.L. 2010. Enlightenment after the Enlightenment: American Transformations of Asian Contemplative Traditions. Doctoral Thesis. Houston, TX: Rice University.

Goenka, S.N. 1997. Discourse Summaries. Onalaska WA: Vipassana Research Institute.

Fazzino, L.L. 2014. Leaving the Church Behind: Applying a Deconversion Perspective to Evangelical Exit Narratives. Journal of Contemporary Religion. 29:2, 249-266.

Mapel, T. 2007. The Adjustment Process of Ex-Buddhist Monks to Life after the Monastery. Journal of Religion and Health. 46:1, 19-34.

Pagis, M. 2008. Cultivating Selves: Vipassana Meditation and the Microsociology of Experience. Doctoral Thesis. Illinois: The University of Chicago.

Pagis, M. 2010. Producing Intersubjectivity in Silence: An Ethnographic Study of Meditation Practice. Ethnography. 11:2, 309-328.

Rahmani, M. 2017. Drifting Through Samsara: Tacit Conversion and Disengagement in Goenka's Vipassana Movement in New Zealand. Doctoral Thesis. Dunedin: University of Otago.

Rahmani, M., and Pagis, M. 2015. "Vipassana Meditation." WRSP. At http://www.wrl drels.org/profiles/VipassanaMeditation.htm. Accessed 22/2/ 2017.

Sharf, R.H. 2015. Is mindfulness Buddhist? (And Why it Matters). Transcultural Psychiatry. 52:4, 470-484.

Snow, D.A., and Machalek, R. 1983. The Convert as a Social Type. Sociological Theory. 1, 259-289.

Streib, H., Silver, C.F., Csöff, R-M., Keller, B., and Hood, R.W. 2011. Deconversion: Qualitative and Quantitative Results from Cross-Cultural Research in Germany and the United States of America. Göttingen: Vandenhoeck \& Ruprecht.

Wright, S.A. 2007. The Dynamics of Movement Membership: Joining and Leaving New Religious Movements. In: D.G. Bromley, ed. Teaching New Religious Movements. Oxford: Oxford University Press, 187-210.

Wright, S.A., and Ebaugh, H.R.F. 1993. Leaving New Religions. In: D.G. Bromley \& J. Hadden, eds. Cults and Sects in America. Greenwich, CT: Associations for the Sociology of Religion and JAI Press, 117-138. 